\title{
BMJ Open Is the public supportive and willing to pay for a national assistive reproductive therapies programme? Results from a multicountry survey
}

\author{
Chris Skedgel (D) , ${ }^{1}$ Eleanor Ralphs, ${ }^{2}$ Elaine Finn, ${ }^{2}$ Jennifer A Whitty, ${ }^{3}$ \\ Marie Markert, ${ }^{4}$ Carl Samuelsen ${ }^{4}$
}

To cite: Skedgel C, Ralphs E, Finn $\mathrm{E}$, et al. Is the public supportive and willing to pay for a national assistive reproductive therapies programme? Results from a multicountry survey. BMJ Open 2021;11:e044986. doi:10.1136/ bmjopen-2020-044986

- Prepublication history and supplemental material for this paper is available online. To view these files, please visit the journal online (http://dx.doi org/10.1136/bmjopen-2020044986).

Received 18 September 2020 Revised 13 December 2020 Accepted 10 February 2021

\section{Check for updates}

\section{(c) Author(s) (or their} employer(s)) 2021. Re-use permitted under CC BY-NC. No commercial re-use. See rights and permissions. Published by BMJ.

${ }^{1}$ Office of Health Economics, London, UK

${ }^{2}$ IQVIA, London, UK

${ }^{3}$ Norwich Medical School, University of East Anglia,

Norwich, UK

${ }^{4}$ Ferring Pharmaceuticals, København, Denmark

Correspondence to

Dr Chris Skedgel;

cskedgel@ohe.org

\section{ABSTRACT}

Objectives To understand attitudes towards infertility and willingness to pay (WTP) towards a publicly funded national assistive reproductive therapies (ART) programme.

Design Attitudes survey with dichotomous and openended WTP questions.

Setting Online survey administered in the USA, UK, Spain, Norway, Sweden, Finland, Denmark and China.

Participants 7945 respondents, analysed by country. Nordic respondents were pooled into a regionally representative sample.

Primary and secondary outcome measures Primary outcome measures were proportion of sample agreeing with different infertility-related and ART-related value statements and supporting a monthly contribution to fund a national ART programme, expressed in local currency. Secondary outcome measure was maximum WTP.

Results Across the nationally representative samples, $75.5 \%$ of all respondents agreed with infertility as a medical condition and $82.3 \%$ and $83.7 \%$ with ART eligibility for anyone who has difficulty having a baby or a medical problem preventing them from having a baby, respectively. $56.4 \%$ of respondents supported a defined monthly contribution and $73.9 \%$ supported at least some additional contribution to fund a national ART programme. Overall, converting to euros, median maximum WTP was $€ 3.00$ and mean was $€ 15.47$ (95\% Cl 14.23 to 16.72 ) per month. Maximum WTP was highest in China and the USA and lowest in the European samples.

Conclusions This large, multicountry survey extends our understanding of public attitudes towards infertility and fertility treatment beyond Europe. It finds evidence that a majority of the public in all sampled countries/ regions views infertility as a treatable medical condition and supports the idea that all infertile individuals should have access to treatments that improve the chance of conception. There was also strong agreement with the idea that the desire for children is a basic human need. WTP questions showed that a majority of respondents supported a monthly contribution to fund a national ART programme, although there is some evidence of an acquiescence bias that may overstate support among specific samples.
Strengths and limitations of this study

- The survey elicits attitudes towards infertility and fertility treatment and presents a dichotomous willingness to pay (WTP) question, limiting anchoring effects and extreme responses, as well as a maximum WTP question across five countries/regions.

- The dichotomous WTP amount was based on rough estimates of per-capita costs of a national fertility treatment programme in each country, but these should not be taken as a definitive estimate of the cost of fertility treatment in each country.

- Responses to attitudinal and WTP questions were descriptively summarised by country but not analysed for significant differences between countries, as the study design cannot account for potentially important cultural and health system differences between the countries.

- The top $1 \%$ of maximum WTP responses from each country/region were excluded from the Tobit analysis to moderate the effect of any extreme or 'protest' responses.

\section{INTRODUCTION}

Data from the Organisation for Economic Co-operation and Development (OECD) show that global fertility rates have been declining steadily over the past 50 years to the point that they are now below population replacement levels in most OECD countries. ${ }^{1}$ Theories explaining the cause of this decline tend to centre on the demographic transition from high-birth, high-mortality rates to lowbirth, low-mortality rates in most countries, which is associated with delays in marriage and childbearing and smaller families relative to pretransition levels. ${ }^{23}$ Delays in childbearing, along with population health trends including increasing obesity rates, a rise of sexually transmitted diseases and evidence of decreasing sperm quality, ${ }^{4}$ means that an increasing number of prospective parents are experiencing some degree of infertility. ${ }^{56}$ 
Boivin $e t a l^{6}$ reviewed the studies of the prevalence of infertility and found 12-month infertility rates ranging from $3.5 \%$ to $16.7 \%$ in more developed countries. They also found that although an average of $56.1 \%$ of infertile individuals/couples sought medical care, only $22.4 \%$ actually received care. This gap highlights the barriers to patient access to fertility treatments, more specifically known as assistive reproductive therapies (ART).

As fertility rates decline, the proportion of elderly citizens in a population grows, leading to skewed population demographics, potential labour shortages and an increasing dependency ratio leading to increasing burdens on working age adults to maintain existing public services and benefits. ${ }^{7}$ To address declining fertility rates, governments are increasingly considering different elements of a 'population policy mix', including promoting access to ART for infertile individuals/couples. ${ }^{57}$ However, evidence on public support for national ART programmes, particularly in terms of willingness to pay (WTP), is limited. A key study by Rauprich et $a l^{8}$ in Germany found that more than three-quarters of all respondents supported full or partial public coverage of ART, including respondents identifying as patients, reproductive care physicians, medical ethicists, social lawyers, 'health politicians' and the general public. They also reported that $57 \%$ of the general public $(n=1005)$ supported a hypothetical $€ 1.50$ per month increase in healthcare insurance premiums to fund a national ART programme in Germany. Support for public funding was strongly associated with views of infertility as a disease; that there is a need for assisted reproduction for infertile couples; and that every human should have the opportunity to have children.

A multicountry survey of public attitudes towards ART was conducted by Fauser et $a^{\ominus}$ in six European countries (France, Germany, Italy, Spain, Sweden, UK; n=6110). Overall, they found that $93 \%$ of respondents supported at least one publicly funded cycle of ART and up to six or more funded cycles, with support peaking at between two and three cycles $(28 \%$ and $23 \%$ of all respondents, respectively), although this support was not elicited in the context of a specific taxpayer contribution. Based on the substantial difference between general 'support' and a specific WTP observed by Rauprich et $a l^{8}$, it is likely public WTP for such a programme will be lower than this general support. Other studies have explored patient WTP for ART, ${ }^{10-14}$ but a patient perspective is less useful than a public perspective when considering the value of a taxpayer-funded programme.

In this study, we sought to build on the results of Rauprich $e t a l$ by seeking to understand public support and WTP for a nationally funded ART programme in five countries/regions: USA, UK, Spain, China and the Nordic region. In the following sections, we describe the methodology and results of a survey of nationally representative samples, including attitudes towards infertility and eligibility for ART and WTP a country-specific monthly contribution towards a national ART programme. We find that support for this contribution varies by country and is significantly associated with respondent attitudes and demographics.

\section{METHODS \\ Survey design}

The online survey was administered in two parts. In the first part, a nationally representative sample of respondents were asked about their demographic characteristics, including age, income and any experience with infertility or ART treatment, as well as their attitudes towards infertility and fertility treatment. Respondents indicated agreement or disagreement with a series of statements about infertility and different ART eligibility criteria. Following these, respondents were asked to indicate their WTP a country-specific contribution each month to fund a national ART programme. In a follow-up question, respondents were asked the maximum amount they would be willing to pay as an open-ended question. Respondents who were not willing to pay the presented amount were constrained to an amount between zero and the threshold amount. Respondents who were willing to pay the presented amount were constrained to an amount greater than this figure.

The country-specific monthly contribution was calculated based on an assumption that all eligible infertility patients in a country in any year would receive an average of three funded cycles of in vitro fertilisation (IVF) or intracytoplasmic sperm injection (ICSI). This assumption is consistent with the support observed by Fauser et al as well as the most common threshold for publicly funded cycles in European countries, although it varies between one and six cycles in different countries. ${ }^{15}$ The number of persons-female and male-likely to seek ART was based on estimates of reproductive age populations in each country and estimates of the prevalence of infertility and the probability of seeking fertility treatment from Boivin et al. ${ }^{6}$ The average cost per cycle of treatment was derived from country-specific estimates from IVF Worldwide,$^{16}$ updated to 2020 costs using country-specific price indices. The distribution of treatments (IVF or ICSI) within this overall average was based on treatment proportions observed in human fertility reports from UK and Sweden. ${ }^{17-19}$ The calculated country-specific amounts are shown in table 1 in local currency along with the equivalent sum in euros $(€)$. Only the local currency amount was shown to respondents; euros are included for comparability between countries/regions in the analysis of responses.

In the second part of the questionnaire, respondents who indicated that they had experience with infertility or ART participated in a discrete choice experiment (DCE) to elicit the relative importance of different aspects of ART, including effectiveness, adverse effects and cost. This manuscript focuses on the attitudes and WTP of the full sample, with the DCE results reported elsewhere. 
Table 1 Willingness to pay per month thresholds and results by country/region

\begin{tabular}{|c|c|c|c|c|c|}
\hline Country & $\begin{array}{l}\text { Dichotomous } \\
\text { WTP threshold, } \\
\text { local currency }\end{array}$ & $\begin{array}{l}\text { Dichotomous } \\
\text { WTP threshold (€) }\end{array}$ & $\begin{array}{l}\text { Median } \\
\text { maximum } \\
\text { WTP (€) }\end{array}$ & $\begin{array}{l}\text { Mean maximum WTP }(95 \% \mathrm{CI}) \text {, } \\
\text { local currency* }\end{array}$ & $\begin{array}{l}\text { Mean maximum WTP } \\
(95 \% \mathrm{Cl}), €^{\star}\end{array}$ \\
\hline UK & $£ 2.42$ & 2.68 & 1.11 & $£ 4.43$ (3.51 to 5.35$)$ & 4.91 (3.89 to 5.93) \\
\hline USA & US\$6.60 & 5.57 & 4.22 & US\$29.38 (24.27 to 34.49$)$ & 24.77 (20.46 to 29.09 ) \\
\hline Spain & $€ 2.49$ & 2.49 & 3.00 & $€ 8.72$ (7.26 to 10.19$)$ & $8.72(7.26$ to 10.19$)$ \\
\hline Denmark & DKK26.01 & 3.49 & & & \\
\hline Finland & $€ 1.97$ & 1.97 & & & \\
\hline Norway & NOK20.67 & 1.94 & & & \\
\hline Full sampleł & - & - & 3.00 & - & 15.47 (14.23 to 16.72$)$ \\
\hline
\end{tabular}

Conversions as of 6 August 2020, https://www.xe.com/.

*Estimates exclude top $1 \%$ of maximum WTP responses to trim outliers.

†The Nordic countries use a mix of currencies and cannot be summarised individually.

$\ddagger$ The full data set was used for the calculations of median WTP and the trimmed data set for the calculation of mean WTP.

DKK, Danish krone; NOK, Norwegian krone; SEK, Swedish krona; WTP, willingness to pay.

\section{Patient and public involvement}

There was no patient or public involvement in the design, conduct or reporting of this research. We intend to disseminate the results of this research via patient advocacy organisations.

\section{Study population}

Samples were recruited from survey panels maintained by Dynata in the USA, UK, Spain, China, Denmark, Sweden, Norway and Finland. These countries were chosen to represent a diverse, though by no means comprehensive, cross section of attitudes towards infertility and WTP for publicly funded fertility treatments.

Individuals who had registered to receive survey invitations from Dynata received an email inviting them to learn more about the study. Following the accompanying link took them to an online participant information sheet which outlined the purpose of the study and provided a voluntary link to the questionnaire. Respondents were required to check a box indicating their consent to participate in the survey before they could proceed to the questionnaire. Respondents who submitted a completed questionnaire were rewarded by the survey provider with 'points' that can be accumulated and redeemed for rewards. Potential respondents continued to be recruited until the predefined sample quotas were met.

A small convenience sample $(n=25)$ was initially recruited from each country/region to pilot the survey. Respondents completed the survey and were then asked to rate the difficulty and length of the survey on a 5-point Likert scale, from very easy/short to much too difficult/ long. Dropout rates in each country were also tracked. The pilot identified an issue around the currency symbols presented to some respondents and this was corrected in the final version of the questionnaire. Ratings of the length and difficulty of the survey did not flag concerns around the perceived length or difficulty, and dropout rates were comparable across the countries/regions in the sample. Based on these results, we proceeded to the main survey.

An age-gender representative sample was recruited from each country (or region, in the case of the Nordic countries), and this was supplemented by an 'over-sample' of reproductive age respondents to ensure additional statistical power for the DCE phase of the study. To ensure the representativeness of the sample, respondent quotas in each country were defined by gender and age group, and once a demographic quota for the WTP sample was filled, it was closed to respondents with the same characteristics. The oversample is excluded from the analysis of WTP to maintain national representativeness. Sample size in the main survey was informed by Dynata's advice on the number of respondents necessary to ensure reasonable demographic representativeness in each country.

\section{Statistical analysis}

All WTP analyses were based on the nationally representative sample. Due to the small populations of the individual Nordic countries, participants from these countries were pooled into a combined Nordic sample that was representative of the region rather than the individual countries. This seemed justifiable given similarities in the way the healthcare is organised and funded, as well as expectations of similar ethical values, across these countries.

Responses to the demographic and attitudinal questions were descriptively summarised by country but not analysed for significant differences between countries. For the analysis of dichotomous WTP, a logistic model was used to analyse the impact of individual demographics and attitudes on individual WTP the threshold amount. For the analysis of maximum WTP, a Tobit model was used to account for the fact that the dependent variable was 


\begin{tabular}{|c|c|c|c|c|c|c|c|}
\hline $\begin{array}{l}\text { Country or } \\
\text { region }\end{array}$ & $\begin{array}{l}\text { Total } \\
\text { respondents }\end{array}$ & $\%$ female ${ }^{*}$ & $\begin{array}{l}\% \text { married } \\
\text { or long-term } \\
\text { relationship* }\end{array}$ & $\begin{array}{l}\% \text { tried } \\
\text { to have a } \\
\text { baby* }\end{array}$ & $\begin{array}{l}\% \text { tried } \geq 12 \\
\text { months }^{*} \dagger\end{array}$ & $\begin{array}{l}\% \text { received } \\
\text { medical } \\
\text { assistance } †\end{array}$ & $\begin{array}{l}\% \text { successful } \\
\text { following } \\
\text { treatment }{ }^{\star} \dagger\end{array}$ \\
\hline China & 1524 & 46.5 & 84.4 & 79.7 & 61.2 & 40.3 & 85.4 \\
\hline Nordics & $1894 \ddagger$ & 50.1 & 63.7 & 65.9 & 29.6 & 15.3 & 67.6 \\
\hline Spain & 1512 & 51.0 & 76.0 & 69.1 & 48.6 & 30.5 & 74.7 \\
\hline UK & 1513 & 51.0 & 70.5 & 64.3 & 37.4 & 15.6 & 73.1 \\
\hline USA & 1502 & 52.3 & 67.7 & 61.3 & 40.0 & 25.2 & 76.2 \\
\hline
\end{tabular}

*All proportions exclude respondents who declined to answer.

†Conditional on having tried to have a baby.

‡Denmark 512; Finland 512; Norway 360; Sweden 510.

meaningfully censored at zero and therefore not normally distributed. A Tobit model accounts for censoring in estimates of the regression coefficients and their SEs. The top $1 \%$ of WTP responses from each country/region were excluded from the Tobit analysis to trim extreme outliers. Each country/region was analysed separately and statistical significance was judged at the 0.05 level.

\section{RESULTS}

The survey was administered online in February 2020 and there were a total of 7945 respondents in the age-gender nationally representative WTP samples. The number of respondents by country is summarised in table 2 along with key characteristics. The age distribution of respondents was similar between countries and the most notable difference was in the proportion of respondents over the age of 60 . Older respondents represented roughly $20 \%$ of the sample from the Nordics, UK and USA, $14 \%$ of the Spanish sample and 7\% of the Chinese sample. Comparison with national age-gender distributions (see online supplemental figure 1) showed a reasonable correspondence between national and sample age-gender distributions, although females older that 60 were relatively under-represented in all samples, particularly in Spain and China. Males older than 60 were also relatively underrepresented in some samples, but to a lesser extent than females.

\section{Attitudes towards infertility and ART eligibility}

Respondent attitudes towards infertility are summarised in figure 1. In general, there was strong support for statements that infertility is a medical condition (but not an illness), that the desire for children is a basic human need, that the opportunity to have children should be available to everyone and that the infertile should have access to treatments that improve the chance of pregnancy. Support for ART eligibility by recipient characteristics is summarised in figure 2. Overall support was highest for persons with a medical problem preventing them from having a baby and lowest for those who already have one or more children or have previously received ART. Finally, support for ART eligibility by recipient age and sex is summarised in figure 3. Support peaked for patients between 30 and 39 years old, with support for older patients higher than for younger patients. Support for female eligibility was slightly but statistically significantly higher than for males in all countries/regions.

\section{Dichotomous WTP}

Overall, $56.4 \%$ of respondents were willing to pay the country-specific contribution. WTP was highest in China (78.9\% of respondents) and Spain $(61.9 \%)$ while slightly less than half of all respondents supported the increase in the USA, Nordics and UK $(48.8 \%, 47.6 \%$ and $46.7 \%$, respectively). The proportion willing to make some contribution, even if it was less than the country-specific amount, was $73.9 \%$ across the sample, ranging from
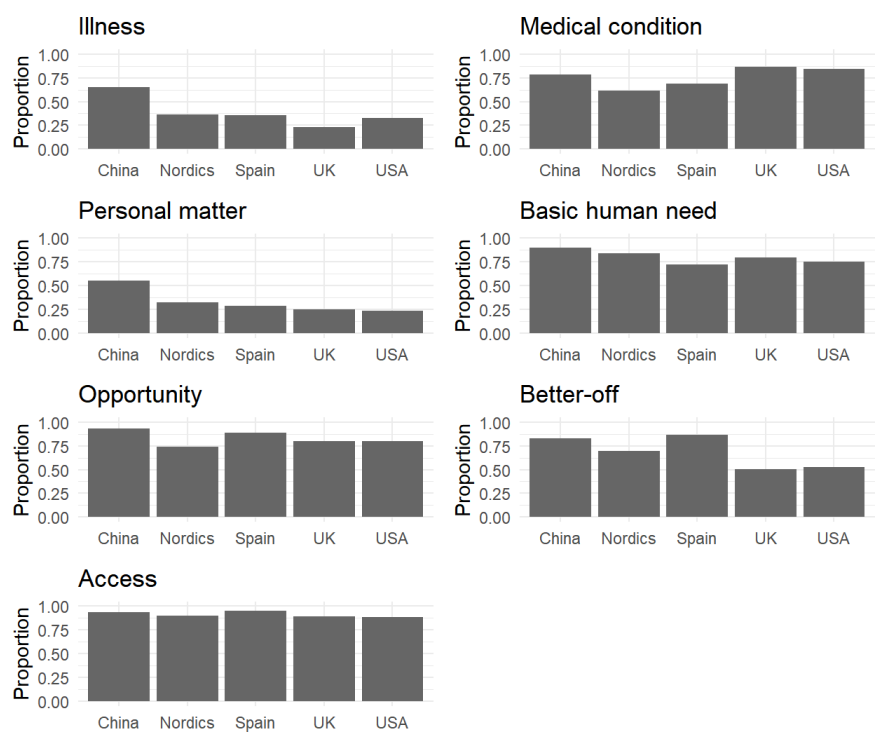

Figure 1 Attitudes towards infertility. Illness: 'Infertility is an illness'. Medical condition: 'Infertility is a medical condition'. Personal matter: 'Infertility is a personal matter and it is ethically wrong to treat it as a medical condition'. Basic human need: 'The desire for children is a basic human need'. Opportunity: 'The opportunity to have children should be available to everyone'. Better off: 'Society is better-off if more people can have children'. Access: 'Infertile women and men should have access to treatments that improve their chances of pregnancy'. 


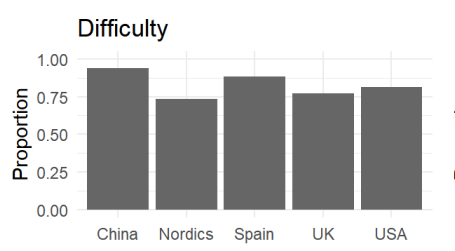

No spouse/partner

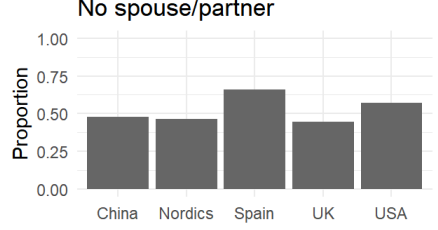

Children via ART

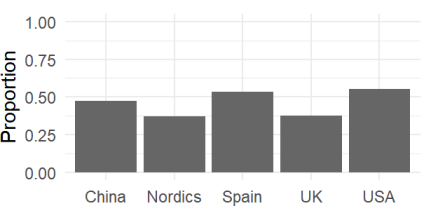

Figure 2 Support for fertility treatment eligibility. Difficulty: 'Anyone who has difficulty having a baby'. Medical problem: 'Anyone with a medical problem preventing them from having a baby'. No spouse/partner: 'Anyone without a spouse or long-term partner'. Children: 'Anyone who already has one or more children'. Children via ART: 'Anyone who have already had one or more children with assistance of ART'. Low chance: 'Anyone with a low chance of a successful pregnancy, even with treatment'. ART, assistive reproductive therapies.

93.4\% in China to $65.9 \%$ in the Nordics (Spain $74.1 \%$; USA $70.5 \%$; UK $67.3 \%$ ).

The predictors of agreement with the dichotomous WTP question were similar to the drivers of maximum WTP, discussed in more detail below.

\section{Maximum WTP}

Maximum WTP by country/region is presented in table 1, expressed in local currency and euros for comparability, and shows that respondents from USA (€24.77
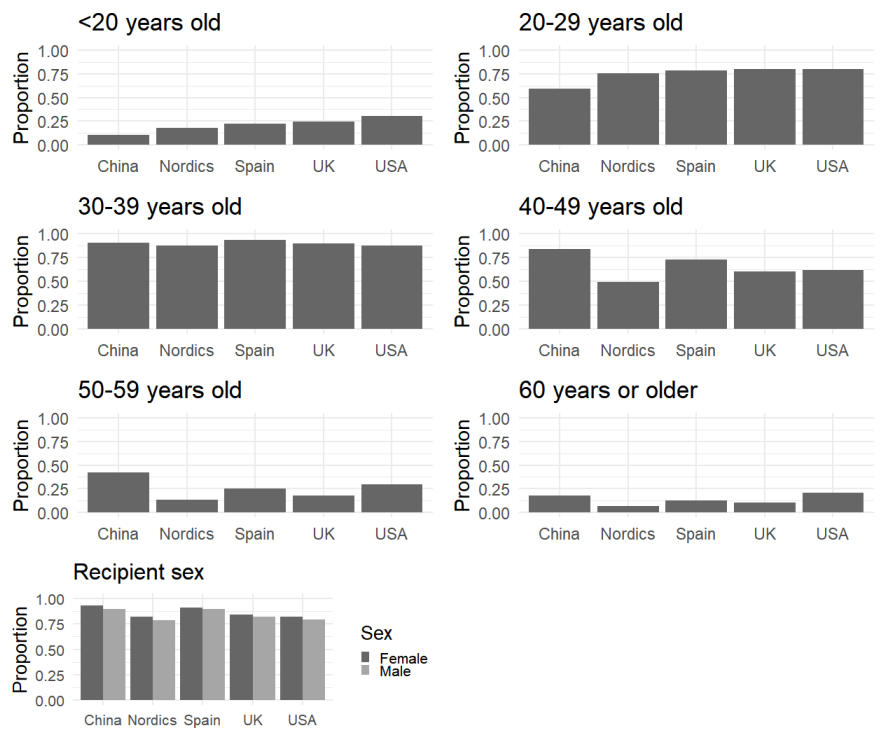

Figure 3 Support for eligibility by recipient age and sex.

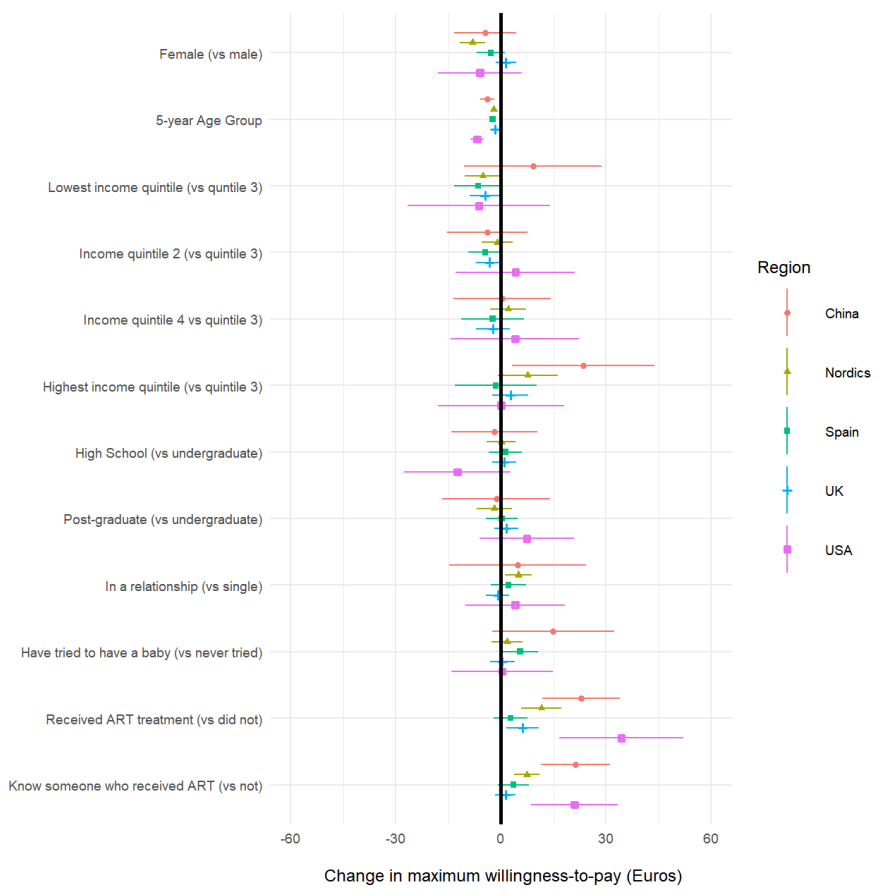

Figure 4 Drivers of maximum willingness to pay (WTP) by respondent characteristics. Figure excludes primary education category due to small $n$. ART, assistive reproductive therapies.

per month) and China (€34.07 per month) had a significantly and substantially higher mean maximum WTP than respondents from the European countries (between $€ 4.91$ and $€ 8.72$ per month). These figures exclude the top $1 \%$ of maximum WTP values but the substantial difference between the mean and median values indicates that there are still some extreme responses in the data, particular among the USA and China samples.

Results of the Tobit regression of maximum WTP with respect to respondent characteristics, attitudes towards infertility and attitudes towards eligibility are illustrated in figures 4-6, respectively. Detailed regression results by parameter and country/region are available in the online supplemental material. Figure 4 shows that maximum WTP was positively and significantly associated with having received fertility treatment in the past or knowing someone who had, and negatively associated with the respondent's age. Women tended to have a lower maximum WTP than men, controlling for education and income. Figure 5 shows that the associations between attitudes towards infertility and maximum WTP were heterogeneous between national samples. In particular, USA and China tended to move in opposite directions. The greatest divergence was in the association between maximum WTP and the statement that all people deserve an opportunity for children. Agreement dramatically increased maximum WTP in the USA but dramatically decreased maximum WTP in China. Finally, figure 6 shows that supporting eligibility for anyone who has difficulty conceiving, and those without a spouse 


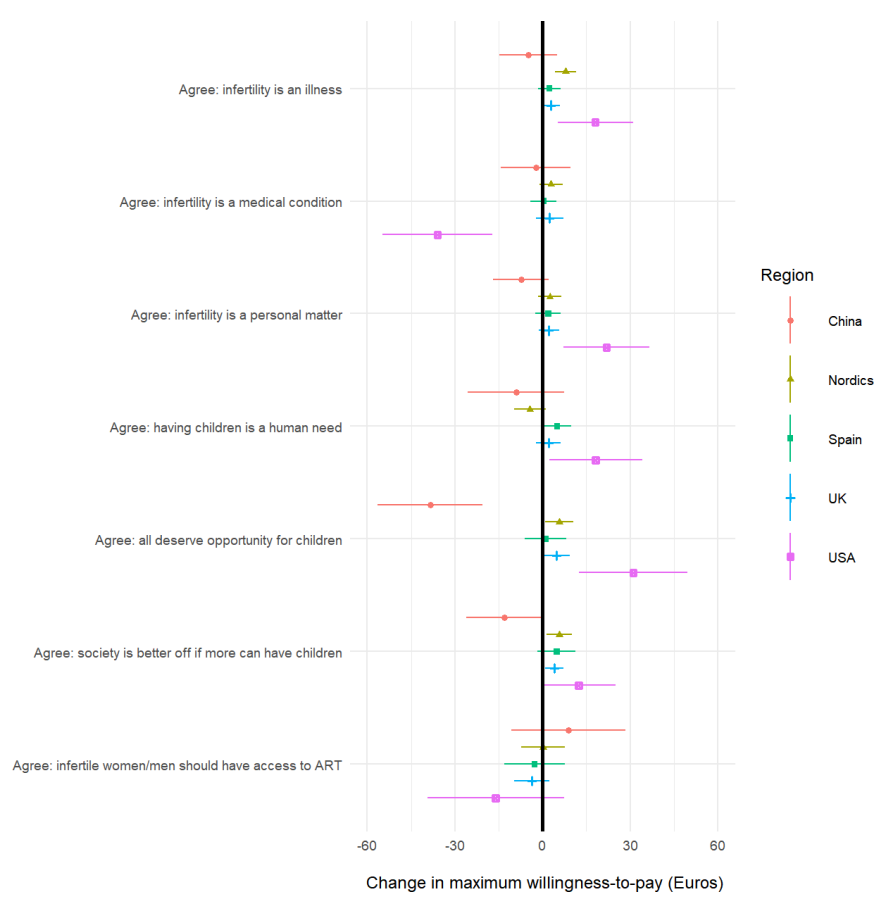

Figure 5 Drivers of maximum willingness to pay (WTP) by attitudes towards infertility (vs disagree). ART, assistive reproductive therapies.

or long-term partner, was associated with a significantly greater maximum WTP in almost all countries.

\section{DISCUSSION}

Our large, multicountry study found that a majority of respondents in our age-gender nationally representative

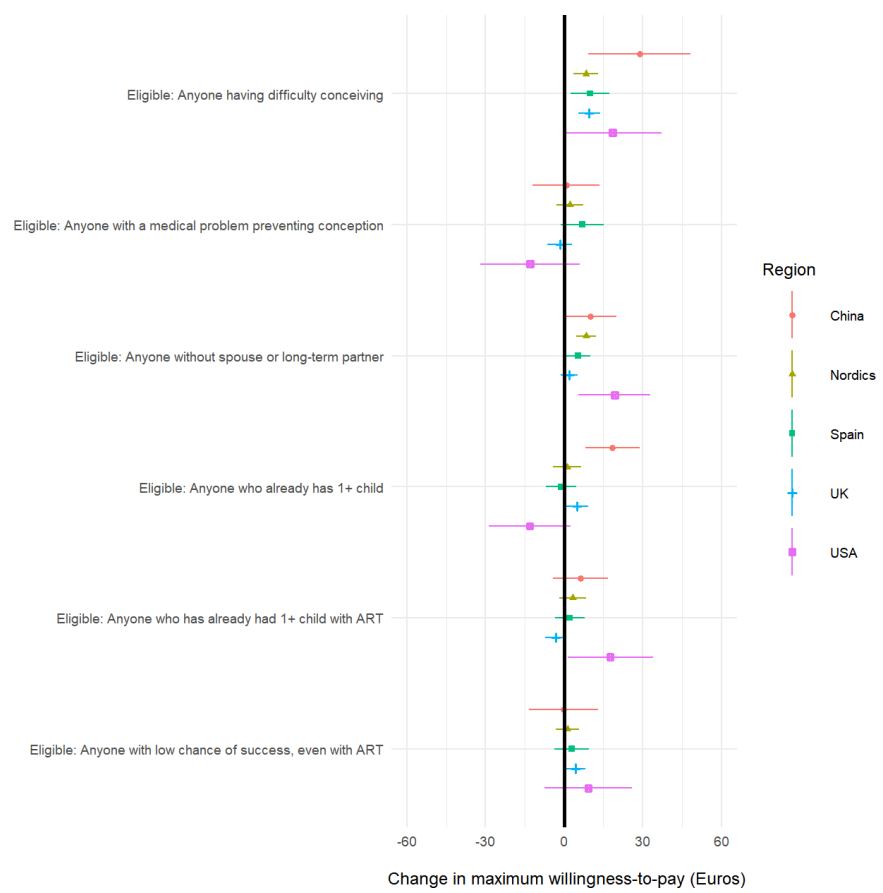

Figure 6 Drivers of maximum willingness to pay (WTP) by agreement towards eligibility (vs disagree). ART, assistive reproductive therapies. public samples agree with infertility as a medical condition and support the idea that all infertile individuals should have access to treatments that improve the chance of conception. A majority was also in agreement with the idea that the desire for children is a basic human need. Importantly, the WTP questions showed that respondents also supported some increase in their taxes or insurance premiums to fund a national ART programme. A majority of respondents in China and Spain supported a contribution that could fund an average of three cycles of ART for anyone with infertility, as part of a publicly funded national programme. Support for this specific amount was weaker in the other countries but there was a majority support for at least some public contribution to a national ART programme.

This survey extends our understanding of public attitudes towards infertility and WTP for publicly funded treatments beyond the strictly European context of previous studies ${ }^{8}{ }^{9}$ by including the USA and China, countries with very different demographic and fertility profiles from Europe, and potentially different views on infertility and public funding for ART. We followed Rauprich $e t a l^{8}$ in the design of our WTP questions in eliciting dichotomous WTP for a specific monthly contribution to support a national ART programme. Their finding of $57 \%$ public WTP was very similar to the $56 \%$ overall proportion we observed, supporting the robustness of this finding, although it is important to note that this level of support was not evenly distributed across all countries in our sample. Like Rauprich $e t a l^{8}$ and Fauser $e t a l{ }^{9}$ we also find strong agreement for the notion that all persons who have difficulty conceiving should be able to access ART and that this support drops for those who already have one or more children. Our respondents were consistent in giving greater support to recipients aged 30-39 over other age groups, particularly recipients less than 20 or older than 50, and in showing a slight preference for female over male recipients. Most respondents favoured access for anyone having trouble conceiving, regardless of the probability of success, although support fell for people who already had children (with or without ART).

Interestingly, agreement with eligibility for respondents not in a long-term relationship-a potentially controversial statement-was associated with a statistically significantly higher maximum WTP in every sample except the UK (where it was positive but insignificant). Eligibility for those not in a long-term relationship was supported by just over half of the respondents in the sample, although it was notably higher in Spain and the USA. We speculate this view may represent a strong personal belief in universal access to ART and this is reflected in a higher WTP for a national programme, but further qualitative research would be required to confirm this hypothesis.

Substantive cultural and health system differences between the countries in the study make direct comparison between national samples difficult, and the study design did not allow us to control for these factors. However, some crude country-specific results do stand 
out. Most clearly, the US and Chinese samples stand out from the others in terms of their maximum WTP towards a publicly funded ART programme. However, some of the key drivers of this maximum WTP differed between the two samples. The association between maximum WTP and agreement with eligibility for individuals who already had one or more children was strongly positive in the Chinese sample but negative in the US sample. The reverse pattern was seen with respect to agreement with the statement that all persons deserve an opportunity for children, where the association was strongly negative in the Chinese sample and strongly positive in the US sample. A similar but less extreme pattern was seen around the association between agreement that society is better off if more people can have children: agreement was associated with a lower maximum WTP in the Chinese sample and a positive WTP in the US sample. The negative association between maximum WTP and agreement with greater opportunities for children in the Chinese sample may represent something of a protest response, if these respondents felt it should be the state's responsibility to pay for fertility treatment and were therefore less willing to support a specific levy for such treatments. This is speculation, but these patterns do highlight differences in cultural attitudes towards aspects of infertility and, arguably, the role of public funding of ART, between countries in the study.

More than half of the Chinese respondents expressed support for the notion of infertility as a medical condition and as a personal matter that should not be treated as a medical condition. This contradictory result, combined with a high degree of support in the dichotomous WTP question, may suggest some degree of acquiescence, or 'yea-saying', bias among Chinese respondents, by which some respondents have a tendency to favour positive responses. ${ }^{20}$ However, there was also a slightly higher proportion of younger respondents in the Chinese sample relative to the other counties, and this was associated with a higher WTP relative to older age groups. More broadly, table 2 suggests a high proportion of respondents across all countries reported having tried to have a baby and having received medical assistance, particularly in the Chinese sample. These rates suggest that individuals with experience with ART may have been more motivated to participate in the survey and therefore may be overrepresented in the sample.

The potential for hypothetical or protest responses is a limitation of most contingent valuation (WTP) studies. ${ }^{21}{ }^{22}$ Other studies of WTP in the context of infertility have attempted to elicit maximum WTP from a recipient perspective and have reported strong start point or framing effects using payment card and openended elicitation formats. ${ }^{10-13}$ We sought to minimise these sources of bias by eliciting dichotomous WTP for a small, monthly figure rather than a larger and potentially more abstract annual figure. We also framed the question around a concrete and policy-relevant figure rather than attempting to elicit naive maximum WTP values. We believe this more conservative approach to estimating WTP enhances the robustness of the results. We caution that our subsequent estimates of maximum WTP are likely to be anchored on the figure presented in initial dichotomous question. We also trimmed the top $1 \%$ of maximum WTP values to reduce the impact of extreme responses, although the substantial difference between mean and median maximum WTP indicates that some extreme values remain. This highlights the tension between excluding implausible or protest responses without imposing research expectations and respecting individual rationality. ${ }^{23}$ In the absence of an objective indication that a specific response may be irrational or unconsidered, we chose to include the broadest sample possible. We note that dichotomous and maximum WTP increased with respondent income quintile, consistent with economic theory and supporting the face validity of the results.

An additional limitation is that our estimates of the percapita cost of national ART programmes in the different study countries, which encompass very different health systems and funding mechanisms, are relatively crude. The estimates were further complicated by the wide range of public and private prices for ART in most countries. The purpose of these calculations was not to estimate a percapita cost of an ART programme in each country but to generate reasonably comparable reference points to estimate dichotomous WTP in each country. It is likely that the precise per-capita cost of a national ART programme in any specific study country will be more or less than the sum we presented to respondents. This is particularly true for the Nordic estimate, which is not specific to any of the component countries. Future research should seek to more precisely estimate the cost of national ART programmes based on country-specific ART cost per cycle and rates of infertility and care seeking. This last parameter is itself likely to be dependent on the existence of publicly funded treatment options, further complicating the estimation.

Fertility rates in most wealthy countries have fallen below population replacement levels and governments are having to consider different aspects of their 'population policy mix', including improving access to ART. ${ }^{157}$ This study builds on previous findings and confirms strong support for the principle of universal ART access for all infertile individuals across all the countries in the survey. Importantly, it also demonstrates that most respondents support at least some increase in their taxes or insurance premiums to fund this access.

Correction notice This article has been corrected since it was published. In the 'Setting' section of the Abstract, Spain has been included in the study countries.

Acknowledgements Employees of Ferring Pharmaceuticals participated as authors in the study and contributed to the design of the questionnaire, the interpretation of data, and the drafting and review of the manuscript. Ferring Pharmaceuticals approved the decision to submit the manuscript.

Contributors This work was a joint effort. All authors (CSk, ER, EF, JAW, MM, CSa) made substantial contributions to the conception of the study and the design and wording of the questionnaire. CSk, ER, EF and MM developed the estimates of 
the cost of ART in each country. CSk, ER and EF contributed to the data analysis and visualisation. All authors (CSk, ER, EF, JAW, MM, CSa) contributed to the interpretation of data. CSk, ER and EF produced the first draft of the manuscript, and JAW, MM and CSa made substantial intellectual contributions to the final draft. All authors (CSk, ER, EF, JAW, MM, CSa) provided their approval for submission and agreed to be named on the publication. All authors (CSk, ER, EF, JAW, MM, $\mathrm{CSa}$ ) agree to be accountable for all aspects of the work, and to ensure that any questions related to the accuracy and integrity of any part of the work are appropriately investigated and resolved.

Funding This work was funded by Ferring Pharmaceuticals as contracted research.

Competing interests CSk, ER and EF report grants from Ferring Pharmaceuticals during the conduct of the study. JAW reports personal fees from Ferring Pharmaceuticals during the conduct of the study. MM reports other from Ferring Pharmaceuticals during the conduct of the study; other from Ferring Pharmaceuticals outside the submitted work. CSa reports personal fees from Ferring Pharmaceuticals during the conduct of the study.

\section{Patient consent for publication Not required.}

Ethics approval The participant information sheet, the questionnaire and the statistical analysis plan were reviewed and approved by the University of East Anglia Faculty of Medicine and Health Science Ethics Committee, Norwich, UK (reference 201819-090).

Provenance and peer review Not commissioned; externally peer reviewed.

Data availability statement Anonymous data are available upon reasonable request to the corresponding author, subject to approval by Ferring Pharmaceuticals.

Supplemental material This content has been supplied by the author(s). It has not been vetted by BMJ Publishing Group Limited (BMJ) and may not have been peer-reviewed. Any opinions or recommendations discussed are solely those of the author(s) and are not endorsed by BMJ. BMJ disclaims all liability and responsibility arising from any reliance placed on the content. Where the content includes any translated material, BMJ does not warrant the accuracy and reliability of the translations (including but not limited to local regulations, clinical guidelines, terminology, drug names and drug dosages), and is not responsible for any error and/or omissions arising from translation and adaptation or otherwise.

Open access This is an open access article distributed in accordance with the Creative Commons Attribution Non Commercial (CC BY-NC 4.0) license, which permits others to distribute, remix, adapt, build upon this work non-commercially, and license their derivative works on different terms, provided the original work is properly cited, appropriate credit is given, any changes made indicated, and the use is non-commercial. See: http://creativecommons.org/licenses/by-nc/4.0/.

\section{ORCID iD}

Chris Skedgel http://orcid.org/0000-0003-4989-8846

\section{REFERENCES}

1 OECD. Fertility rates 2020

2 Pablos-Mendez A, Radloff SR, Khajavi K, et al. The demographic stretch of the Arc of life: social and cultural changes that follow the demographic transition. Glob Health Sci Pract 2015;3:341-51.

3 Kirk D. Demographic transition theory. Popul Stud 1996;50:361-87.
4 Virtanen HE, Jørgensen N, Toppari J. Semen quality in the 21st century. Nat Rev Urol 2017;14:120-30.

5 Ledger WL. Demographics of infertility. Reprod Biomed Online 2009:18:S11-14.

6 Boivin J, Bunting L, Collins JA, et al. International estimates of infertility prevalence and treatment-seeking: potential need and demand for infertility medical care. Hum Reprod 2007;22:1506-12.

7 Grant J, Hoorens S, Gallo F. Should art be part of a population policy mix? A preliminary assessment of the demographic and economic impact of assisted reproductive technologies, 2006. Available: https://www.rand.org/pubs/documented_briefings/DB507.html [Accessed 15 Jun 2020].

8 Rauprich O, Berns E, Vollmann J. Who should pay for assisted reproductive techniques? Answers from patients, professionals and the general public in Germany. Hum Reprod 2010;25:1225-33.

9 Fauser BCJM, Boivin J, Barri PN, et al. Beliefs, attitudes and funding of assisted reproductive technology: public perception of over 6,000 respondents from 6 European countries. PLoS One 2019;14:e0211150

10 Dieng A, He J, Poder TG. Web comparison of three contingent valuation techniques in women of childbearing age: the case of ovulation induction in Quebec. Interact J Med Res 2020;9:e13355.

11 Settumba SN, Shanahan M, Botha W, et al. Reliability and validity of the contingent valuation method for estimating willingness to pay: a case of in vitro fertilisation. Appl Health Econ Health Policy 2019;17:103-10.

12 Gonen LD, Bokek-Cohen Y. Valuing the invaluable: do emotional experiences during fertility treatments affect the willingness to pay for them? Eur Rev Appl Psychol 2018;68:45-60.

13 Poder TG, He J, Simard C, et al. Willingness to pay for ovulation induction treatment in case of who II anovulation: a study using the contingent valuation method. Patient Prefer Adherence 2014;8:1337-46.

14 Palumbo A, De La Fuente P, Rodríguez M, et al. Willingness to pay and conjoint analysis to determine women's preferences for ovarian stimulating hormones in the treatment of infertility in Spain. Hum Reprod 2011;26:1790-8.

15 Calhaz-Jorge C, De Geyter Ch, Kupka MS, et al. Survey on ART and IUI: legislation, regulation, funding and registries in European countries. Hum Reprod Open 2020;2020.

16 IVF Worldwide. The costs of IVF in different countries, 2008. Available: https://ivf-worldwide.com/education/introduction/ ivf-costs-worldwide/the-costs-of-ivf-in-different-countries.htm [Accessed 30 Mar 2020].

17 Human Fertilisation \& Embroyology Authority. Fertility treatment 2017: trends and figures, 2019. Available: https://www.hfea.gov.uk/ media/2894/fertility-treatment-2017-trends-and-figures-may-2019. pdf [Accessed 30 Mar 2020].

18 Sundhedsdata-Styrelsen. Assisteret reproduktion 2017, 2019. Available: https://sundhedsdatastyrelsen.dk/da/tal-og-analyser/ analyser-og-rapporter/andre-analyser-og-rapporter/assisteretreproduktion [Accessed 30 Mar 2020].

19 Nationellt kvalitetsregister for assisterad befruktning Fertilitetsbehandlingar I Sverige Årsrapport 2019, 2019.

20 Podsakoff PM, MacKenzie SB, Lee J-Y, et al. Common method biases in behavioral research: a critical review of the literature and recommended remedies. J Appl Psychol 2003;88:879-903.

21 Arrow K, Solow R, Portney P. Report of the NOAA panel on contingent valuation, 1993.

22 Loomis J. What's to know about hypothetical bias in stated preference valuation studies? J Econ Surv 2011;25:363-70.

23 Miguel FS, Ryan M, Amaya-Amaya M. 'Irrational' stated preferences: a quantitative and qualitative investigation. Health Econ 2005;14:307-22. 